\title{
Variations in the Promoter Region of the Apolipoprotein A-1 Gene Influence Plasma Lipoprotein(a) Levels in Asian Indian Neonates from Singapore
}

\author{
CHEW-KIAT HENG, POH-SIM LOW, AND NILMANI SAHA \\ Department of Paediatrics, National University of Singapore, Singapore 119074
}

\section{ABSTRACT}

We studied the influence of two DNA polymorphisms $(-75$ bp $\mathrm{G} / \mathrm{A}$ and $+83 \mathrm{bp} \mathrm{C} / \mathrm{T})$ in the promoter region of the apolipoprotein A-1 (apoA1) gene on cord plasma level of lipoprotein(a) $[\mathrm{Lp}(\mathrm{a})]$ in 1076 newborns of both genders from the three major ethnic groups in Singapore-Chinese, Malays, and Asian Indians. The frequency of the $A$ allele at $-75 \mathrm{bp}$ in the Indians was significantly lower than the Chinese and Malays. There was no linkage disequilibrium between the two sites studied. Both polymorphic sites were not significantly associated with any lipid factors except for $\mathrm{Lp}$ (a) levels in the Asian Indians. The $A A$ and $C C$ homozygotes were significantly associated with lower Lp(a) levels. These associations were specific only to the male Indian neonates. The genetic variations at the -75 and +83 bp explained $6.9 \%$ and $7.2 \%$, respectively, of the total variability of plasma Lp(a) levels at birth in the Asian Indians. The Lp(a) levels were also significantly different between composite genotypes in the order $G G / T T>G A / C T>G G / C T>G A / C C>$ $G G / C C>A A / C C$. The effects of the two polymorphisms seem to be additive as the composite genotypes were able to explain $14 \%$ of the $\mathrm{Lp}(\mathrm{a})$ variance, equivalent to the sum of the two constituent sites. Our results showed that there is significant ethnic- and gender-specific influence of the apoA1 gene on plasma Lp(a) levels at birth that is inherent and independent of known geneenvironment interactions. (Pediatr Res 49: 514-518, 2001)

apoA1, apolipoprotein A-1

\section{Abbreviations}

Lp(a), lipoprotein(a)

CAD, coronary artery disease
ApoA1 is the predominant protein that is associated with the HDL cholesterol (HDLC) particle. Both HDLC and apoA1 are key components of the reverse cholesterol transport process and are inversely correlated with the risk of CAD.

Both genetic and environmental factors influence plasma HDLC and apoA1 levels $(1,2)$. There is evidence to link polymorphisms in the apoA1 gene to CAD prevalence and incidence $(3,4)$. Population and clinical studies suggest a major locus involved in the control of plasma HDLC and apoA1 (5-8). Recently, however, three groups reported that Tangier disease, a rare recessive disorder characterized by an extremely low HDLC and an apoA1 level of only $2-3 \%$ of normal range, is caused by mutations in the ATP-binding cassette transporter1 gene (9-11).

Received February 24, 2000; accepted November 29, 2000.

Correspondence: P.S. Low, Department of Paediatrics, National University of Singapore, 5, Lower Kent Ridge Road, Singapore 119074; e-mail: paelowps@nus.edu.sg

Supported by grant NMRC/0234/1997 from the National Medical Research Council of Singapore.

Present affiliation for N.S.: Division of Molecular Genetics, John Curtin School of Medical Research, The Australian National University, ACT-2601, Australia.
The gene for apoA1 is located on the long arm of chromosome 11 together with the apolipoprotein C-3 and apolipoprotein A-4 genes $(12,13)$. A common polymorphism described in the apoA1 promoter region consists of a $G$ to $A$ substitution at the $75 \mathrm{bp}$ upstream of the transcription start site. Many studies have found consistent association of this polymorphism with HDLC levels in several populations (14-21) but not in others (22-24). ApoA1 production rate was shown to be significantly lower in $G / A$ human subjects than $G G$ homozygotes (22). Lower promoter activity $(22)$ and expression rate $(22,25)$ were observed in vitro with the $A$ allele. However, another study found that the $A$ allele significantly decreased the binding affinity of a nuclear factor that enhanced the transcription efficiency of the promoter (26). In a meta-analysis (27) comprising over 3000 healthy subjects, the rare allele $A$ was associated with mildly increased apoA1 levels of about 5 $\mathrm{mg} / \mathrm{dL}$.

Recently, another $M s p$ I polymorphic site was identified in the first intron of apoA1 gene, creating a $C-T$ and/or $G-A$ transition at the $+83 \mathrm{bp}$ and/or $+84 \mathrm{bp}$ (28). These sequence variations were shown to be associated with increased HDLC levels $(29,30)$. Both the -75 bp and +83 bp sites were 
significantly predictive of CAD severity in terms of the number of diseased vessels in a case-control study (31). There was another report of higher $A$ allele frequency in myocardial infarction patients relative to healthy control subjects (32) but not for alleles at the $+83 \mathrm{bp}$.

Association studies of apoA1 polymorphisms with lipid quantitative traits have thus far been carried out in adult populations. Such studies had to take into consideration the confounding nongenetic factors such as effects of smoking, diet, and medication on lipid profiles of the subjects. To be free from the confounding effects of the above environmental factors, we undertook this study with neonatal cord blood samples from the Chinese, Malay, and Asian Indian populations of Singapore. The Asian Indians will henceforth be referred to as Indians. As cord plasma lipid levels have yet to be influenced by any known environmental factors, any genotype-specific association of the apoA1 promoter gene polymorphisms with cord plasma lipid levels would reflect the extent of genetic control at birth.

\section{MATERIALS AND METHODS}

Study subjects. A sample of 1076 cord blood obtained from normal newborns of Chinese, Malay, and Indian heritage were studied. Participating babies had no history of mixed heritage in the preceding three generations. Verbal informed consent was obtained from parents of the newborns for inclusion of their child for this study. The details of sample collection and methods of lipid and lipoprotein level estimation were as reported in our earlier studies $(33,34)$. This study was approved by the National Medical Research Council of Singapore.

Isolation of DNA and genotyping of ApoA1 polymorphisms. Genomic DNA was extracted from leukocytes obtained from the cord blood samples by the sarcosine method (35). The ApoA1 polymorphisms were identified by PCR. A 433-bp fragment in the $5^{\prime}$ region of the ApoAl gene was amplified by using the following primers: sense, 5' AGG GAC AGA GCT GAT CCT TGA ACT CTT AAG 3 ' and antisense, 5' TTA GGG GAC ACC TAG CCC TCA GGA AGA GCA 3' (21). PCR was performed in a volume of $20 \mu \mathrm{L}$ containing $1-10 \mu \mathrm{g}$ of genomic DNA, 20 pmol of each primer, $0.5 \mathrm{mM}$ of each deoxyribonucleoside triphosphate (dNTP), reaction buffer, $2 \%$ DMSO, and $1.0 \mathrm{U}$ of Taq DNA polymerase. Amplified products were digested with $10 \mathrm{U}$ of $M s p \mathrm{I}$ at $37^{\circ} \mathrm{C}$ overnight and the digested fragments were size-fractionated in $2 \%$ NuSieve (BioWhittaker, Rockland, ME, U.S.A.) agarose gel with incorporated ethidium bromide and photographed over a UV transilluminator.

The presence of the restriction site at $-75 \mathrm{bp}$ ( $G$ allele) and at $+83 \mathrm{bp}$ ( $C$ allele) resulted in four fragments of $209 \mathrm{bp}, 113$ bp, $66 \mathrm{bp}$, and $45 \mathrm{bp}$. The absence of the restriction site at -75 bp ( $A$ allele) resulted in three fragments of $209 \mathrm{bp}, 179 \mathrm{bp}$, and $45 \mathrm{bp}$. The absence of the restriction site at $+83 \mathrm{bp}$ ( $T$ allele) created a larger fragment of $254 \mathrm{bp}$ instead of two fragments of $209 \mathrm{bp}$ and $45 \mathrm{bp}$.

Statistical analysis. Statistical analysis was performed using SPSS for Windows (release 9, SPSS, Inc., Chicago, IL,
U.S.A.). The significance of differences for the means of plasma total cholesterol (TC), triglycerides (TG), HDLC, LDL cholesterol (LDLC), apoA1, apolipoprotein B (apoB), and $\mathrm{Lp}$ (a) levels between races and gender were determined by the $t$ test or ANOVA as appropriate. Allelic frequencies of the apoA1 gene polymorphisms were estimated by gene counting and $95 \%$ confidence intervals by the following formula: frequency $\pm 1.96[p(1-p) / n]^{1 / 2}$ where $p$ is the allele frequency and $n$ is the total number of chromosomes. The $\chi^{2}$ analysis was used to test for Hardy-Weinberg equilibrium and the $z$ test for differences in allele frequencies between groups. Test of independence between the two apoA1 polymorphic sites was also estimated by the $\chi^{2}$ statistic, and the strength of their associations (linkage disequilibrium) was determined by the correlation coefficient, $\Delta$, according to Chakravarti et al. (36). ANOVA was performed to determine the effects of the apoA1 gene polymorphisms on the various lipid traits in the different ethnic groups after adjustment for significant covariates. The significance of the sample variance was tested by $F$ and $p$ values and percentage of explained variance $\left(R^{2} \times 100\right)$ was calculated from the sum of squares. Due to skewed distribution, the raw data for TG and $\mathrm{Lp}(\mathrm{a})$ were transformed by natural logarithm before comparison by $t$ test and ANOVA. Because the raw values of triglycerides and $\mathrm{Lp}$ (a) in cord blood specimens were small, with most values below 1 , and as the $\ln$ of $<1$ is negative, logarithmic transformation for these parameters were carried out following addition of 1 to the raw values. Statistical significance was taken at the 0.05 level.

\section{RESULTS}

The genotype and allelic frequencies of both the apoA1 polymorphisms in the three ethnic groups are presented in Table 1. Genotype distributions were all consistent with a population at Hardy-Weinberg equilibrium except for the +83 bp site in the Indians. The marginal deviation was due to the presence of one rare homozygous $T T$ subject. It was not likely that any of the assumptions for Hardy-Weinberg equilibrium were violated, and we attribute such departure from equilibrium to chance. The allele frequency of $A$ at $-75 \mathrm{bp}$ in the Indians was significantly lower than both the Chinese and the Malays, whereas the $T$ allele at +83 bp was significantly lower than the Chinese only. The two sites were not in linkage disequilibrium for all ethnic groups. Details of linkage disequilibrium tests are given in Table 2.

Cord plasma $\mathrm{Lp}(\mathrm{a})$ levels were not significantly different between genders in all the three ethnic groups. However, correlations of $\mathrm{Lp}$ (a) levels with other lipid traits were genderspecific. Spearman's correlation test showed Lp(a) levels to be weakly but significantly correlated with TC only in the females of all ethnic groups. Significant correlations with HDLC were also relatively stronger in the females compared with the males. In the Chinese only, $\mathrm{Lp}$ (a) levels were also significantly correlated with LDLC and TG in the females, and apoA1 in both genders. In the Indians, $L p(a)$ levels were only significantly correlated with gestational period in the females. The Spearman's correlation coefficients for each subgroup are presented in Table 3 . Traits that were significantly correlated with 
Table 1. Genotype and allele frequencies of the two $5^{\prime}$ end polymorphisms at the -75 and +83 site in the neonates of three ethnic groups of Singapore

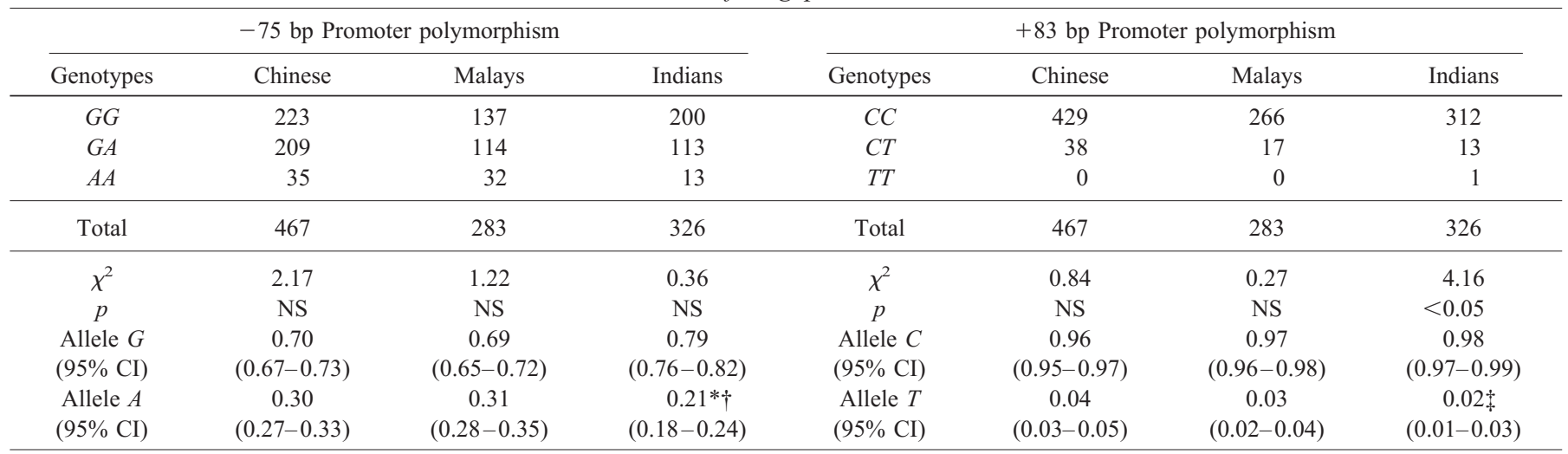

Significantly different from * Chinese $(p<0.0001)$, $\uparrow$ Malays $(p<0.0001)$, and $\$$ Chinese $(p<0.05)$ by $z$ test.

CI, confidence interval.

Table 2. Linkage disequilibrium between the $-75 \mathrm{bp}$ and $+83 \mathrm{bp}$ polymorphic sites

\begin{tabular}{cccc}
\hline & Chinese & Malays & Indians \\
\hline$\chi^{2}$ & 1.29 & 0.76 & 1.27 \\
$p$ & 0.52 & 0.68 & 0.87 \\
$\Delta$ & -0.01 & 0.02 & 0.01 \\
\hline
\end{tabular}

$\mathrm{Lp}$ (a) levels were incorporated into the respective ANOVA as covariates to eliminate their confounding effects on $L p(a)$ levels when determining the influence of the polymorphic sites.

Among the lipid factors, only Lp(a) was found to be significantly associated with the two polymorphisms studied (Table 4). Nonsignificant results other than $\mathrm{Lp}$ (a) were not shown. The significant effect of both $-75 \mathrm{bp}$ and $+83 \mathrm{bp}$ sites was ethnicity specific for Indians only. Significantly lower plasma $\mathrm{Lp}$ (a) levels were found in $A A$ and $C C$ homozygotes. When analysis was carried out separately on the genders, we found that the effects of both $-75 \mathrm{bp}$ and +83 bp polymorphisms were confined to Indian male neonates only, whereas effects on the Chinese and Malays remained insignificant for both genders.

To examine the combined effects of both polymorphic sites, we used groupings based on composite genotypes. They were significantly associated with $\mathrm{Lp}(\mathrm{a})$ levels $(F=6.4, p<$ 0.0005 ) in the male Indian neonates. Consistent with the effect of individual polymorphisms, subjects bearing the composite genotype of $A A / C C$ had the lowest $\mathrm{Lp}(\mathrm{a})$, whereas subjects who carried the $T$ allele had higher Lp(a) level. Together, both polymorphisms could explain $14 \%$ of the total $L p(a)$ variation. The effects from the two sites appeared to be additive, as each could explain an equal proportion of $7 \%$. The composite genotype and their corresponding means of transformed Lp(a) are also presented in Table 4. In a two-way ANOVA using both sites as independent variables, the interaction term was not significant. This indicates that their effects on Lp(a) levels were independent of each other. This is also supported by the lack of linkage disequilibrium between the two sites.

\section{DISCUSSION}

The allele frequencies of the two polymorphic sites in the Asian populations showed significant variations among the ethnic groups. In comparison with Caucasian frequencies, the
Malays had the highest frequency, 0.3, for allele $A$, whereas the Indians had a frequency of 0.2. This was closer to the Caucasians, which range from 0.01 to $0.19(14,16,21,29,37)$ and 0.1 in African blacks from Nigeria (38).

In accordance with previous reports $(14-16,21)$, the $A$ allele in our study was associated with higher HDLC and/or apoA1 levels in the Chinese neonates, although the difference did not reach a statistically significant level (results not shown). An opposite trend was observed in the Malays and Indians, but it did not attain statistical significance.

Because the +83 bp polymorphism was described later than the $-75 \mathrm{bp}$, relatively fewer reports on its effect are available. The rare $T$ allele frequency in our study $(0.02-0.04)$ was close to those that were reported for two Caucasian populations with $0.03-0.04(29,30)$ but much lower than the African population of 0.4 (38). Differing from the results reported Caucasians $(29,30)$, we did not find linkage disequilibrium between the two sites. There is also a lack of association of both polymorphic sites with HDLC and ApoA1 levels in our neonate population.

In this study, we found the effects of both the apoA1 polymorphisms on $\mathrm{Lp}$ (a) levels to be ethnicity specific to Indians and gender specific to male neonates only. Malespecific effect of the polymorphism was observed in other studies with European and Icelandic populations $(14,16)$ and in our earlier study on Singaporean Chinese adults (17). However, in Italian adults (15), French Canadians (39), and Europeans from 12 countries (20), the $A$ allele was associated with higher HDLC/ApoA1 in women. It is interesting to note that gender-specific effects of the apoA1 genotypes could already be observed at birth. The possible reasons for such phenomenon has not been elucidated, but the effect of sex hormones would be the likely cause since they are known to affect $\mathrm{Lp}(\mathrm{a})$ levels in adults $(40,41)$, although not without controversies $(42,43)$. In our neonatal subjects, there was no significant difference between $L p(a)$ levels of male and female newborns.

Although there have been many reports on the roles of apoA1 containing lipoproteins and $\mathrm{Lp}(\mathrm{a})$ in atherosclerosis, only one had demonstrated the relationship of these two factors. Liu et al. (44) reported the protective effect of apoA1 on 
Table 3. Spearman's correlation coefficient ( $r$ ) of Lp(a) levels with relevant parameters

\begin{tabular}{|c|c|c|c|c|c|c|c|c|c|c|c|c|}
\hline & \multicolumn{4}{|c|}{ Chinese } & \multicolumn{4}{|c|}{ Malays } & \multicolumn{4}{|c|}{ Indians } \\
\hline & \multicolumn{2}{|c|}{ Males } & \multicolumn{2}{|c|}{ Females } & \multicolumn{2}{|c|}{ Males } & \multicolumn{2}{|c|}{ Females } & \multicolumn{2}{|c|}{ Males } & \multicolumn{2}{|c|}{ Females } \\
\hline & $r$ & $p$ & $r$ & $P$ & $r$ & $P$ & $r$ & $p$ & $r$ & $P$ & $r$ & $P$ \\
\hline Weight & 0.02 & NS & 0.12 & NS & -0.08 & NS & 0.14 & NS & 0.03 & NS & 0.08 & NS \\
\hline $\mathrm{TC}$ & 0.14 & NS & 0.31 & $<0.0005$ & 0.17 & NS & 0.30 & 0.001 & 0.14 & NS & 0.20 & 0.022 \\
\hline HDLC & 0.24 & 0.001 & 0.28 & $<0.0005$ & 0.19 & 0.04 & 0.32 & 0.001 & 0.16 & 0.046 & 0.23 & 0.008 \\
\hline ApoA1 & 0.21 & 0.006 & 0.24 & 0.002 & 0.14 & NS & 0.01 & NS & 0.12 & NS & 0.10 & NS \\
\hline ApoB & 0.13 & NS & 0.15 & NS & 0.03 & NS & 0.06 & NS & 0.10 & NS & 0.07 & NS \\
\hline
\end{tabular}

Table 4. Mean genotypic $\ln [\operatorname{Lp}(a)+1]$ levels in the three ethnic groups

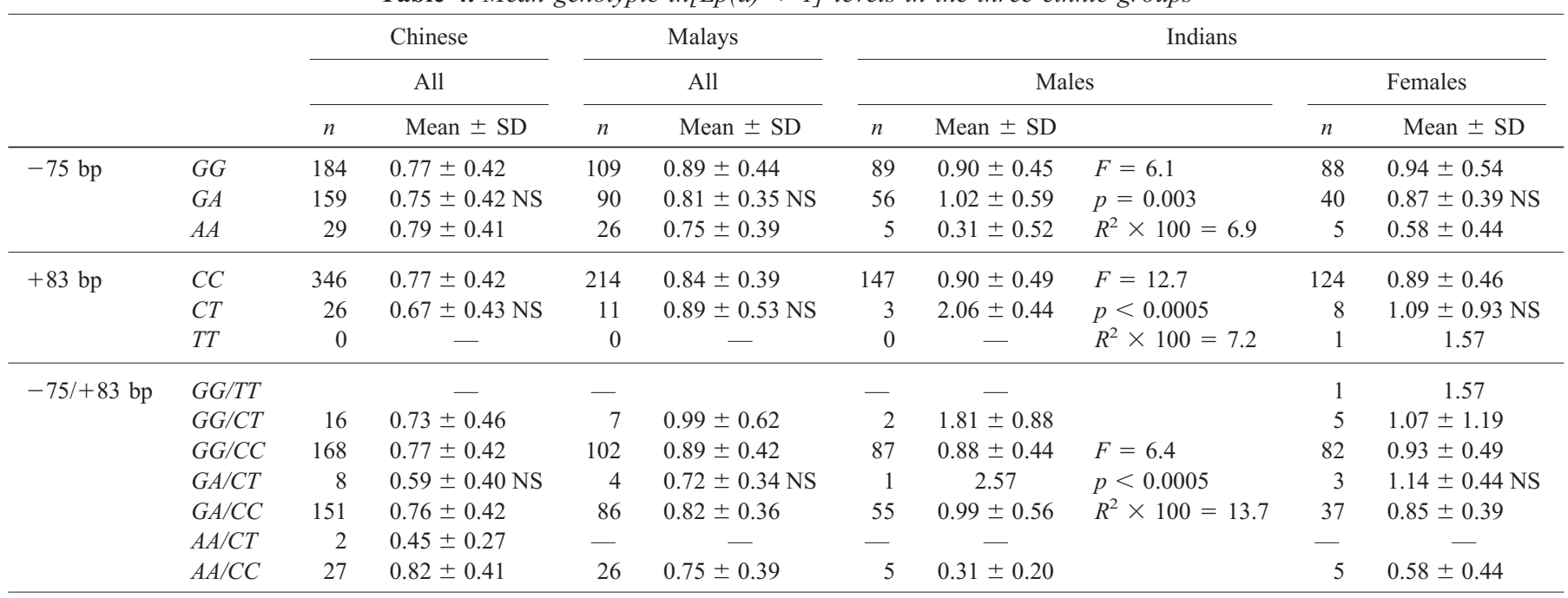

Mean: $\ln [\operatorname{Lp}(\mathrm{a})+1]$

atherosclerosis associated with apo(a) in transgenic mice. Their study showed that mice with the apo(a) transgene that were fed with atherogenic diet had the largest mean lesion area, whereas those with the apoA1 transgene were protected from this effect.

In our study, we found that the two polymorphisms in the apoA1 gene had effect neither on plasma HDLC nor apoA1 levels in all neonates of the three ethnic groups. However, we demonstrated significant associations of the two polymorphic sites with $\mathrm{Lp}$ (a) levels. This is the first study on neonatal population to report such a relationship between the big "A" and small "a." We had earlier reported Lp(a) levels at birth in the three ethnic groups in Singapore and showed correlation of their levels with the mortality rate of their respective ethnic groups (34). This indicates that an individual's level of $L p(a)$ was already determined at birth genetically. Our recent work on apolipoprotein(a) [apo(a)] gene polymorphisms, which included those at the kringle- 4 , pentanucleotide and the $+93 \mathrm{bp}$ sites, had shown that these polymorphisms could explain $17 \%$ of the total variation in $\mathrm{Lp}$ (a) levels at birth (45). When we included the sum of kringle- 4 repeats, pentanucleotide and the +93 bp sites as covariates in the ANOVA model, the effects of both apoA1 genotypes on Lp(a) remained significant (unpublished data), indicating that the associations were independent of apo(a) genotypes. We found in this study that the apoA1 gene could account for nearly as much (14\%) variations in Lp(a) level.
As Scanu (46) pointed out earlier, it is of interest that the characteristics of the apoA1 and the apo(a) proteins, so diverse in nature, could have such influence on each other. At this point, our population study was only able to observe the association of the apoA1 polymorphic sites with $\mathrm{Lp}(\mathrm{a})$ levels, but explanation for the mechanism underlying this effect would have to come from future molecular studies of the interactions between these two genes and proteins.

Acknowledgments. The authors thank Ms. S. Hong for her excellent technical assistance.

\section{REFERENCES}

1. Wilson PW, Anderson KM, Harris T, Kannel WB, Castelli WP 1994 Determinants of change in total cholesterol and HDL-C with age: the Framingham Study. J Gerontol 49:M252-M257

2. Breslow JL, Eisenberg S, Brinton EA 1993 Metabolic determinants of low HDL-C levels. (Review). Ann N Y Acad Sci 1993 676:157-162

3. Ordovas JM, Schaefer EJ, Salem D, Ward RH, Glueck CJ, Vergani PW, Wilson F, Karathanasis SK 1986 Apolipoprotein A-I gene polymorphism associated with premature coronary artery disease and familial hypoalphalipoproteinaemia. N Engl J Med 314:671-677

4. Wile DB, Barbir M, Gallagher J, Myant NB, Ritchie CD, Thompson GR, Humphries SE 1989 Apolipoprotein A-I gene polymorphisms: frequency in patients with coronary artery disease and healthy controls and association with serum apo A-I and HDL-cholesterol concentration. Atherosclerosis 78:9-18

5. Moll PP, Michels W, Weidman WH, Kottke BA 1989 Genetic determination of plasma apolipoprotein A-I in a population-based sample. Am J Hum Genet 44:124139

6. Prenger VL, Beaty TH, Kwiterovich PO 1992 Genetic determination of high density lipoprotein-cholesterol and apolipoprotein A-I plasma levels in a family study of cardiac catheterization patients. Am J Hum Genet 51:1047-1057 
7. Hasstedt SJ, Albers JJ, Cheung MC, Jorde LB, Wilson DE, Edwards CQ, Cannon WN, Ash KO, Williams RR 1984 The inheritance of high density lipoprotein cholesterol and apolipoproteins A-I and A-II. Atherosclerosis 85:21-29

8. Borecki IB, Rao DC, Third JL, Laskarzewski PM, Glueck CJ 1986 A major gene for primary hyperalphalipoproteinemia. Am J Hum Genet 38:373-381

9. Brooks-Wilson A, Marcil M, Clee SM, Zhang LH, Roomp K, van Dam M, Yu L, Brewer C, Collins JA, Molhuizen HOF, Loubser O, Ouelette BFF, Fichter K, Ashbourne-Excoffon KJD, Sensen CW, Scherer S, Mott S, Denis M, Martindale D, Frohlich J, Morgan K, Koop B, Pimstone S, Kastelein JJP, Genest Jr J, Hayden MR 1999 Mutations in ABC1 in Tangier disease and familial high-density lipoprotein deficiency. Nat Genet 22:336-345

10. Bodzioch M, Orso E, Klucken J, Langmann T, Böttcher A, Diederich W, Drobnik W, Barlage S, Büchler C, Porsch-Özcürümez M, Kaminski WE, Hahmann HW, Oette K, Rothe G, Aslanidis C, Lackner KJ, Schmitz G 1999 The gene encoding ATP-binding cassette transporter 1 is mutated in Tangier disease. Nat Genet 22:347-351

11. Rust S, Rosier M, Funke H, Real J, Amoura Z, Piette JC, Deleuze JF, Brewer HB, Duverger N, Denèfle P, Assmann G 1999 Tangier disease is caused by mutations in the gene encoding ATP-binding cassette transporter 1. Nat Genet 22:352-355

12. Karathanasis SK 1985 Apolipoprotein multigene family: tandem organization of human apolipoprotein A-I, C-III and A-IV genes. Proc Natl Acad Sci U S A 82:6374-6378

13. Bruns GA, Karathanasis SK, Breslow JL 1984 Human apolipoprotein A-I C-III gene complex is located in chromosome 11. Arteriosclerosis 4:79-83

14. Jeenah M, Kessling A, Miller N, Humphries SE $1990 \mathrm{G}$ to A substitution in the promoter region of the apolipoprotein A-I gene is associated with elevated A-I and high density lipoprotein cholesterol concentrations. Mol Biol Med 7:233-241

15. Pagani F, Sidoli A, Giudici GA, Barenghi L, Vergani C, Baralle FE 1990 Human apolipoprotein A-I gene promoter polymorphism: association with hyperalphalipoproteinemia. J Lipid Res 31:1371-1377

16. Sigurdsson Jr G, Gudnason V, Sigurdsson G, Humphries SE 1992 Interaction between a polymorphism of the apo A-I promoter region and smoking determines plasma levels of HDL and apo A-I. Arterioscler Thromb 12:1017-1022

17. Saha N, Tay JSH, Low PS, Humphries SE 1994 Guanidine to adenine (G/A) substitution in the promoter region of the apolipoprotein AI gene is associated with elevated serum apolipoprotein AI levels in Chinese non-smokers. Genet Epidemiol 11:255-264

18. Xu C-F, Angelico F, Del Ben M, Humphries SE 1993 Role of genetic variation at the apoA-I-C-III-A-IV gene cluster in determining plasma apo A-I levels in boys and girls. Genet Epidemiol 10:113-122

19. Humphries S, Gudnason V, Paul-Hayse H, Saha N, Rossenneu M 1993 Identification of common genetic polymorphism that determine plasma levels of apo A-I and HDL-C. In: Sirtori CR, Franceschini G, Brewer Jr BH (eds) Human Apolipoprotein Mutants III: Diagnosis and Treatment. Springer-Verlag, Berlin, pp 247-260

20. Talmud PJ, Ye S, Humphries, EARS Group 1994 Polymorphism in the promoter region of the apolipoprotein $\mathrm{AI}$ gene associated with differences in apolipoprotein $\mathrm{A}$ levels. The European Atherosclerosis Research Study. Genet Epidemiol 11:265-280

21. Paul-Hayase H, Rosseneu M, Robinson D, van Bervliet JP, Deslypere JP, Humphries SE 1992 Polymorphisms in the apolipoprotein (apo) A-I-CIII-AIV gene cluster: detection of genetic variation determining plasma apo A-I, apo C-III and apo A-IV concentrations. Hum Genet 88:439-446

22. Smith JD, Brinton EA, Breslow JL 1992 Polymorphism in the human apolipoprotein A-I gene promoter region. Association of the minor allele with decreased production rate in vivo and promoter activity in vitro. J Clin Invest 89:1796-1800

23. Needham EWS, Mattu RK, Rees A, Stocks J, Galton DJ 1994 A polymorphism in the human apolipoprotein AI promoter region. A study in hypertriglyceridaemic patients. Hum Hered 44:94-99

24. Barre DE, Guerra R, Vertraete R, Wang Z, Grundy SM, Cohen JC 1994 Genetic analysis of a polymorphism in the human apolipoprotein A-I gene promoter: effect on plasma HDL-cholesterol levels. J Lipid Res 35:1292-1296

25. Tuteja R, Tuteja N, Melo C, Casari G, Baralle FE 1992 Transcription efficiency of human apolipoprotein A-I promoter varies with naturally occurring A to $\mathrm{G}$ transition. FEBS Lett 304:98-101

26. Angotti E, Mele E, Costanzo F, Avvedimento EV 1994 A polymorphism $(\mathrm{G} \rightarrow \mathrm{A}$ transition) in the -78 position of the apolipoprotein A-I promoter increases transcription efficiency. J Biol Chem 269:17371-17374
27. Juo SH, Wyszynski DF, Beaty TH, Huang HY, Bailey-Wilson JE 1999 Mild association between the $\mathrm{A} / \mathrm{G}$ polymorphism in the promoter of the apolipoprotein A-I gene and apolipoprotein A-1 levels: a meta-analysis. Am J Med Genet $82: 235-241$

28. Wang XL, Badenhop R, Humphrey K, Wilcken DEL 1994 C to T and G to A transitions are responsible for loss of a $M s p l$ restriction site in the 5'-region of the human apolipoprotein AI gene. Hum Genet 95:473-475

29. Wang XL, Badenhop R, Humphrey R, Wilcken DEL 1996 New MspI polymorphism at +83 bp of the human apolipoprotein AI gene: association with increased circulating high density lipoprotein cholesterol levels. Genet Epidemiol 13:1-10

30. Kamboh MI, Aston CE, Nestlerode CM, McAllister AE, Hamman RF 1996 Haplotype analysis of two APOA $1 / M s p$ I polymorphisms in relation to plasma levels of apo A-I and HDL-cholesterol. Atherosclerosis 127:255-262

31. Wang XL, Liu SX, McCredie RM, Wilcken DEL 1996 Polymorphisms at the 5' end of the apolipoprotein AI gene and severity of coronary artery disease. J Clin Invest 98:372-377

32. Reguero JR, Cubero GI, Batalla A, Alvarez V, Hevia S, Cortina A, Coto E 1998 Apolipoprotein A1 gene polymorphisms and risk of early coronary artery disease. Cardiology 90:231-235

33. Low PS, Saha N, Tay JSH, Hong S 1996 Ethnic variation of cord plasma apolipoprotein levels in relation to coronary risk level: a study in three ethnic groups of Singapore. Acta Paediatr 85:1476-1482

34. Low PS, Heng CK, Saha N, Tay JSH 1996 Racial variation of cord plasma lipoprotein(a) levels in relation to coronary risk level: a study in three ethnic groups of Singapore. Ped Res 40:718-722

35. Parzer S, Mannhalter CA 1991 Rapid method of the isolation of genomic DNA from citrated whole blood. Biochem J 273:229-231

36. Chakravarti A, Buetow KH, Antonarakis SE, Waber PG, Boehm CD, Kazazian HH 1984 Nonuniform recombination within the human $\beta$-globin gene cluster. Am J Hum Genet 36:1239-1258

37. Lopez-Miranda J, Ordovas JM, Espino A, Marin C, Salas J, Lopez-Seura F, JimenezPereperez J, Perez-Jimerez F 1994 Influence of mutation in human apolipoprotein A-1 gene promoter on plasma LDL cholesterol response to dietary fat. Lancet 343:12461249

38. Kamboh MI, Bunker CH, Aston CE, Nestlerode CS, McAllister AE, Ukoli FA 1999 Genetic association of five apolipoprotein polymorphisms with serum lipoproteinlipid levels in African blacks. Genet Epidemiol 16:205-222

39. Minnich A, DeLangavant G, Lavigne J, Roederer G, Lussier-Cacan S, Davignon J $1995 \mathrm{G} \rightarrow \mathrm{A}$ substitution at position -75 of the apolipoprotein A-I gene promoterevidence against a direct effect on HDL cholesterol levels. Arterioscler Thromb Vasc Biol 15:1740-1745

40. Albers JJ, Taggart HM, Applebaum-Bowden D, Haffner S, Chesnut III CH, Hazzard WR 1984 Reduction of lecithin-cholesterol acyltransferase, apolipoprotein D and $\mathrm{Lp}$ (a) lipoprotein with the anabolic steroid stanozolol. Biochim Biophy Acta 795:293-296

41. Soma M, Fumagalli R, Paoletti R, Meschia M, Maini MC, Crosignani P, Ghanem K, Gaubatz J, Morrisett JD 1991 Plasma Lp(a) concentration after oestrogen and progestagen in postmenopausal women. Lancet 337:612

42. Denti L, Pasolini G, Ablondi F, Valenti G 1994 Correlation between plasma lipoprotein $\mathrm{Lp}(\mathrm{a})$ and sex hormone concentrations: a cross-sectional study in healthy males. Horm Metab Res 26:602-608

43. Haffner SM, Mykkanen L, Gruber KK, Rainwater DL, Laakso M 1994 Lack of association between sex hormones and Lp(a) concentrations in American and Finnish men. Arterioscler Thromb 14:19-24

44. Liu AC, Lawn RM, Verstuyft JG, Rubin EM 1994 Human apolipoprotein A-I prevents atherosclerosis associated with apolipoprotein(a) in transgenic mice. J Lipid Res 35:2263-2267

45. Low PS, Heng CK, Quek SC, Saha N, MI Kamboh 1999 Significant influence of the +93 C/T polymorphism in the apolipoprotein(a) gene on $\mathrm{Lp}$ (a) concentrations in the Asian Indian neonates from Singapore. Am J Hum Genet 65:A210

46. Scanu AM 1997 From big A to small (a) or vice versa. Circulation 96:1-F 